\section{CardioRenal Medicine}

\title{
The Role of Dendritic and Endothelial Cells in Cardiorenal Syndrome
}

\author{
Grazia Maria Virzìa, b Jun Zhang ${ }^{c}$ Federico Nalesso ${ }^{a}$ b Claudio Ronco ${ }^{a}$ b \\ Peter A. McCullough ${ }^{c-f}$ \\ a Department of Nephrology, Dialysis and Transplant, San Bortolo Hospital, Vicenza, Italy; \\ bIRRIV-International Renal Research Institute Vicenza, Vicenza, Italy; 'Baylor Heart and \\ Vascular Institute, Dallas, TX, USA; d Department of Internal Medicine, Baylor University

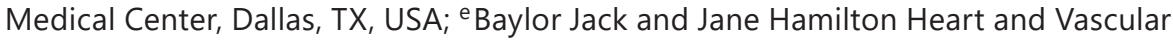

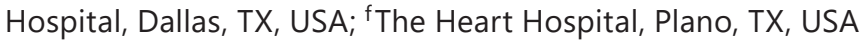

\section{Keywords}

Cardiorenal syndrome - Dendritic cells - Endothelial cells · Endothelial dysfunction · Antigen-presenting cells $\cdot$ Immune dysregulation

\begin{abstract}
Backgrounds: Dendritic cells (DCs) are antigen-presenting cells that play a central role in innate and adaptive immune responses; however, the cross talk between cardiac and renal DCs in cardiorenal syndrome (CRS) has not yet been fully elucidated. In this setting, endothelial cells (ECS) also contribute to immune responses. Summary: DC and EC activation and dysfunction have a central role in the pathogenesis of CRS. Regarding immune responses in CRS, it is unknown whether ECs may serve as antigen-presenting cells or act synergistically with DCs to actively participate in innate and adaptive immune responses. This review first focuses on the burden of concomitant heart and renal DCs in the context of CRS; it examines what is known of DCs in animal models, and proposes a central role for DCs in all types of CRS. Second, this review briefly describes the role of ECs in the context of CRS. Key Messages: Understanding the role of DCs and ECs in immune response could lead to the development of novel therapies for the prevention and treatment of CRS.




\section{Introduction}

Dendritic cells (DCs) are antigen-presenting cells that play a central role in innate and adaptive immunology. The definition of DCs is evolving, and it is now clear that different subsets of these cells have unique roles and functions. In human studies, DCs are involved in immune responses and in a vast array of heart and kidney diseases. Many animal models were used to study DCs, and there is an increasing body of evidence on the role of DCs in combined cardiac and renal disease [1-4]. These animal models may have clinical relevance and may be useful to investigate the role of DCs in cardiorenal syndrome (CRS) in humans. Furthermore, cardiac and renal DCs may be involved in the organ cross talk between heart and kidney diseases. In this context, DCs have been postulated as potential mediators involved in the pathogenesis of CRS.

The critical, dynamic, and bidirectional connections between both acute and chronic cardiac dysfunction and acute and chronic kidney disease are well recognized and classified as CRS. CRS classification system has 5 subtypes whose etymology reflects the primary and secondary pathology, the time frame, and the simultaneous cardiac and renal codysfunction secondary to systemic disease [5,6]. Type 1 CRS represents acute heart failure leading to acute kidney injury (AKI); type 2 CRS represents chronic heart failure leading to kidney failure; type 3 CRS represents AKI leading to acute heart failure; type 4 CRS represents chronic kidney disease leading to heart failure; and type 5 CRS represents systemic disease leading to heart and kidney failure [5-7].

An immune-mediated damage has been postulated as a potential mechanism involved in the pathogenesis of CRS [7]. Alterations in the immune response might include cytokine release and changes in immune cell functions, including apoptosis [8]. Although DCs are potent regulators of immunity, their role in CRS is only partially understood. In this context, there is a pressing and necessary need to translate the findings regarding DCs in animal studies to the human model [7].

In addition, endothelial dysregulation has been increasingly recognized as a contributor to the cross talk between cardiac and renal dysfunction [9-13]. Therefore, endothelial dysfunction has emerged as a critical process in CRS [14]. Recently, endothelial dysregulation has been reported to be associated with type 2 CRS, type 1 diabetes mellitus, and chronic CRS [15-17].

This review will primarily focus on the burden of concomitant heart and renal DCs in the context of CRS; it will examine what is known about DCs in animal models and propose a central role for DCs in all types of CRS. Secondary, this review will briefly describe the role of endothelial cells (ECs) in the context of CRS.

\section{Overview of DCs in Animal Models for Heart and Kidney Diseases}

In 1981, Hart and Fabre conducted a pilot study about DCs in solid organs; in particular, they investigated DCs in the heart and kidney [18]. Specifically, they established the presence of DCs in the heart and in the kidney and characterized them [18]. Three years later, in a rat model, cardiac DCs were found in the connective tissue between myocytes; in addition, renal DCs were distributed in tubules and glomeruli [19]. In 1986, donor major histocompatibility complex (MHC) class II expression was exclusively confined to DCs in a rat model of acute cardiac allograft rejection [20]. Similarly, in 1993, an increased number of OX6 (MHC class II) ${ }^{+}$DCs in the infarcted and border zone, was reported in a rat model of acute myocardial infarction (AMI) [21]. In 2008, Naito et al. [22] studied the different effects of granulocyte colony-stimulating factor (G-CSF) and granulocyte-macrophage colony-stimulating factor (GM-CSF) on infiltration of DCs during early left ventricular (LV) remodeling after AMI. They 
induced AMI by ligation of the left coronary artery in male Wistar rat. G-CSF, a GM-CSF inducer, or saline were administrated for 7 days. They observed that the infiltration by DCs was decreased in rats treated by G-CSF and increased in animals treated by GM-CSF inducer. They concluded that G-CSF improves and GM-CSF exacerbates early postinfarction on LV remodeling in association with modulation of DC infiltration and inflammatory response. In this context, suppression of DC-mediated immunity could be a new promising strategy to treat LV remodeling after AMI [22]. Four years later, DCs were shown to be a potent immunoprotective regulator during the postinfarction healing process in transgenic mice [23]. Based on these findings, cardiac DCs may have detrimental and beneficial effects on AMI [23, 24]. The mechanisms of protection of AMI remodeling by DCs may be related to decrease in proinflammatory macrophages (Ly6C $\mathrm{C}^{\text {high }}$ monocytes), increase in anti-inflammatory macrophages (Ly6C ${ }^{\text {low }}$ monocytes), and production of IL-10 for anti-inflammatory activity [24]. In 1993, DCs, acting as immune effector cells, were observed in a hypertensive rat (SHR) model of Adriamycin-induced cardiotoxicity $[25,26]$; subsequently in 2015 , renal CD $11 \mathrm{c}^{+} / \mathrm{F} 4 / 80^{+}$DCs displayed the phenotypic and functional properties of macrophages in transgenic mice with Adriamycin-induced nephropathy [27]. These data suggest that DCs possess functional plasticity directed by different local environment and stimuli; moreover, DCs have an important role as immune-regulators during steady state as well as serve as a bridge between innate ad adaptive cells in tissue damage and repair.

Additionally, in a rat model with increasing circulating and local angiotensin II (Ang II) levels, Ang II induced renal damage leading to end-organ failure in heart and kidney. Renal DCs expressed MHC class II and CD86 (markers of DC maturation). CD4 $4^{+}$and CD8 ${ }^{+} \mathrm{T}$ cells were infiltrated in the kidney. These findings suggest that Ang II-induced renal damage is involved in innate and adaptive immune response [28]. In 1994, Kaissling and Le Hir [29] studied the characterization and distribution of interstitial cells in the renal cortex of untreated rats. They showed that in healthy kidneys, renal DCs were present in the inner stripe, in the cortex, and in the outer stripe of the medulla. In the same year, Austyn et al. [30] isolated and cultured DCs from heart and kidney in a mouse model; they showed that these nonlymphoid DCs in situ were relatively immature. The distinction between immature and mature DCs is partly based on changes occurring on the phenotypic and functional levels. Phenotypic maturation is attained when DCs upregulate surface maturation ligands such as CD80, CD83, and CD86 along with the MHC class II molecule [20]. Immature DCs are specialized for antigen capture by endocytosis and macropinocytosis, whereas maturing DCs lose these capacities and acquire stimulatory properties for the activation of naive $\mathrm{T}$ cells and for the development of effector T cells [31, 32].

In 2000, Steptoe et al. [33] performed a comparative analysis of DCs in terms of density and total number in transplanted organs in normal C57BL/6 mice using immunohistochemistry (CD45 and MHC class II staining). They revealed that DC density is greater in the heart than in the kidney or in the pancreas in normal mice. Based on this evidence, remarkable advances have been made regarding the role of renal DCs in rodent models of kidney diseases [34]. Notably, renal DCs were shown to ameliorate cisplatin-induced AKI via endogenous production of IL-10, an immunosuppressive cytokine [35, 36]. The protective role of cardiac DCs for AMI remodeling and renal DCs for cisplatin-induced nephropathy may be important for the modulation of innate or adaptive immunity in cardiovascular and renal diseases. In light of the above hypotheses, DCs may provide a potential novel therapy for CRS in humans $[24,37]$. In fact, animal studies have shown that cardiac DCs and renal DCs play a critical role in a variety of cardiac and renal diseases. Although mouse and human DCs differ in some aspects (i.e., some surface markers and cytokine production patterns), basic similarities exist between these species-specific cells [38]. Despite species differences between animals and humans, advances in in vivo or in vitro studies may facilitate patient research regarding CRS. 


\section{Rationale for the Role of DCs in Type 2 and Type 4 CRS}

It is difficult to extract specific mechanisms for type 2 and type 4 CRS based on human studies, which are mainly observational. Therefore, animal studies may provide important insights into the pathogenesis of CRS by mimicking human phenotypes. Many animal studies on cardiac and renal dysfunction have been performed and described in the literature. Information obtained from these animal studies provides insights into the pathogenesis of CRS.

\section{DC-EC Interaction}

Several review and research articles about DC-EC interaction have been published $[2,28$, 39-41]. The interaction between DCs and ECs has been exemplified by a primarily nonimmune double-transgenic rat model, in which hypertension led to cardiac and renal failure induced by Ang II [28]. Muller et al. [28] performed in vivo and in vitro study to investigate the role of Ang II in DC maturation. In the kidney, the tubulointerstitium was infiltrated by 0X62+ DCs and $\mathrm{OX6}^{+}$MHCII DCs. Importantly, renal DCs expressed MHC II and CD86 markers, indicating DC maturation. The endothelium was markedly characterized by intercellular adhesion molecule-1 (ICAM-1). Additionally, renal reactive oxygen species were present, and renal nuclear factor kappa B (NF-кB) was activated [28]. They concluded that Ang II induces dendritic migration, and in vivo TNF- $\alpha$ is involved in DC infiltration and maturation. Furthermore, they suggested that immunosuppression prevents DC maturation and T cell infiltration in a nonimmune model of Ang II-induced renal damage [28]. The role of ICAM-1, transcription factor NF- $\kappa \mathrm{B}$, and TNF- $\alpha$ observed in this study was consistent with the concept of EC activation: activated ECs may express endothelial-leukocyte adhesion molecules, such as E-selectin, and P-selectin. In this context, Robert et al. [40] studied the mechanism by which DCs in blood interact with endothelium. In particular, they used an in vivo model of noninfiltrated murine dermal endothelium. In this model, they observed that E- and P-selectin are present in the dermal endothelium and are involved in the interaction between endothelium and blood DCs. Furthermore, Weis et al. [41] investigated the role of endothelial activation and dysregulation of the nitric oxide pathway in DC adhesion and migration. They reported that the adhesion and migration of DCs are increased by stimuli accelerating atherogenesis. In contrast, increased endothelial nitric oxide synthase activity prevents DC adhesion. Activated DCs are involved in the cross talk between DCs and ECs in angiogenesis through the transdifferentiation into ECs [42].

In DCs, low bioavailability of nitric oxide associated with endothelial activation, dysfunction, and apoptosis enhances the capacity of adhesion and migration through vascular ECs [41]. Activated DCs give rise to DC-EC cross talk in angiogenesis. Furthermore, Zhu et al. [43] reported that homocysteine induces endothelial activation: vascular oxidative stress increases DC adhesion and transmigration induced by homocysteine.

\section{Interaction of Cardiac DCs and Renal DCs}

It is known that Adriamycin (doxorubicin) induces both cardiomyopathy and nephropathy in an SHR model [25-27]. In this condition, this animal model resembles type 2 and type 4 CRS. Immunohistochemical studies revealed that Adriamycin significantly increases the number of $0 X 6$ (MHCII) ${ }^{+}$DCs, ED2 ${ }^{+}$macrophages, $\mathrm{CD} 4^{+}$T helper cells, and $\mathrm{CD} 8^{+} \mathrm{T}$ cytotoxic/ suppressor cells in the heart $[25,26]$. Recently, BALB/c mice showed that renal F4/80 ${ }^{+}$ $\mathrm{CD}_{11 \mathrm{c}^{+}} \mathrm{DCs}$ are present in the cortex in Adriamycin-induced nephropathy [27]. These two animal models showed the complementary relationship between cardiac DCs and renal DCs. This line of evidence suggests the interaction between DCs and dysfunction of the heart and kidney is in type 2 or type 4 CRS. 


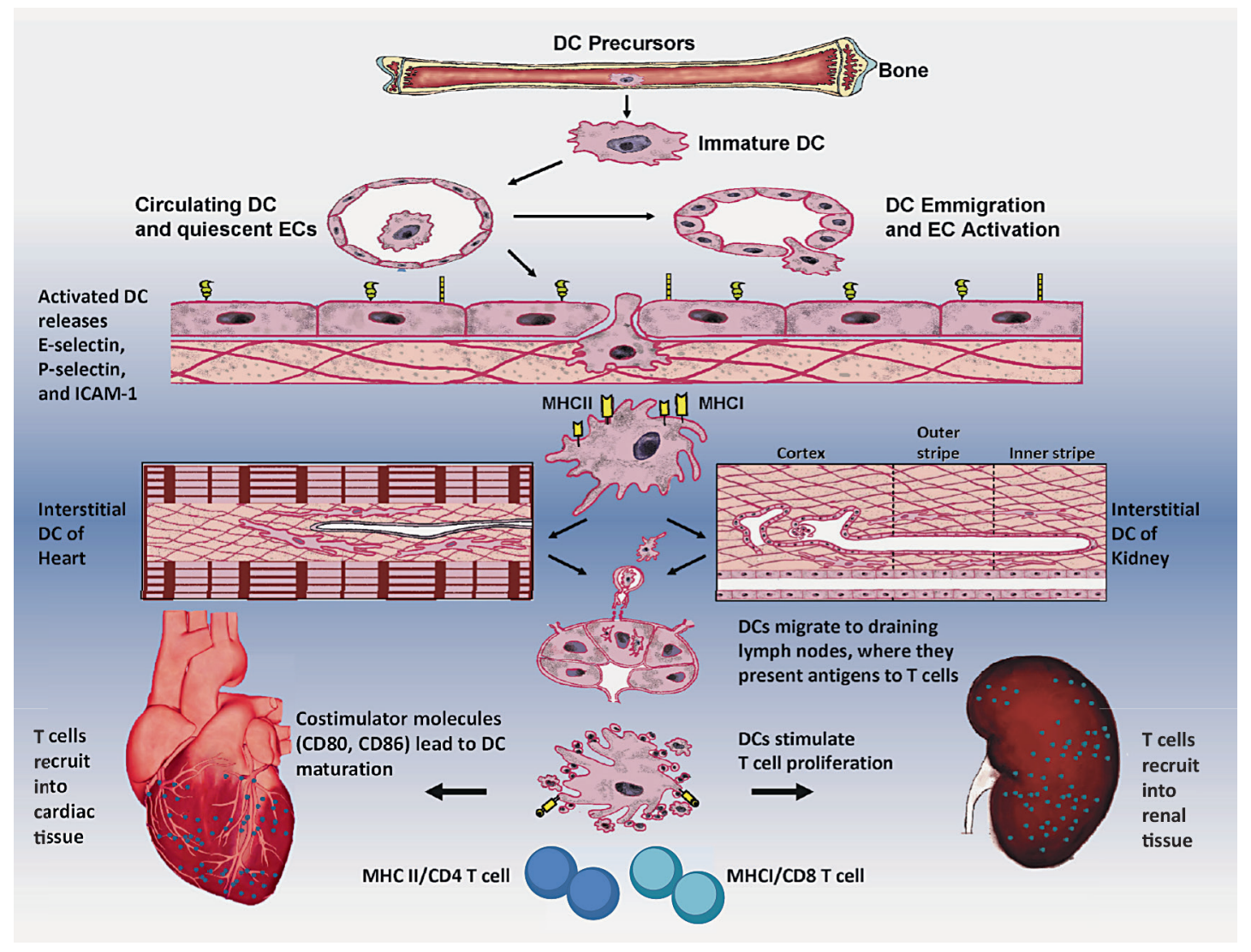

Fig. 1. Schematic diagram showing DCs as professional antigen-presenting cells (APCs), ECs as nonprofessional APCs, and CD4 and CD8 T cells as immune effector cells in the innate and adaptive immune response in CRS, particularly in type 2 and type 4, based on animal studies. The sequence of events leading to the immunity may be described as: (1) DCs are derived from their precursors in bone marrow and circulate in the vessels; (2) upon exposure to cell adhesion molecules (selectins, ICAM-1) on the surface of ECs, DCs can emigrate from blood vessels to the interstitial spaces; (3) immature DCs residing in the heart and kidney have an immature phenotype (a high propensity of antigen capture but relatively poor capacity to stimulate naïve T cells); (4) upon exposure to costimulatory molecules like CD80 and CD86, and danger signals from injured tissues, interstitial DCs with MHC class II (or I) antigen molecules undergo a maturation process; (5) DCs then migrate to draining lymph nodes, where they present antigens to T cells, trigger CD4 or CD8 T cell proliferation; and (6) mature DCs recruit into inflammatory interstitial cardiac and renal tissues, leading to cardiac dysfunction and renal dysfunction, and finally contributing to combined end-organ damage. During this immune process, the cells of innate response are DCs and ECs, whereas the immune cells for adaptive responses are predominant T cells.

\section{Cross Talk between Toll-Like Receptors and DCs}

Toll-like receptors (TLRs), important molecules of the innate immune system, control DC maturation by the upregulation of MHC and costimulatory molecules. TLRs link innate and adaptive immunity and secrete cytokines (IL-1 $\beta$, IL-6, and TNF- $\alpha$ ) and chemokines (keratinocyte chemoattractant- 1 and monocyte chemoattractant protein [MCP]-1) [44]. In addition, TLRs contribute to myocardial inflammation, myocardial dysfunction, ischemia myocardial injury, AMI, cardiac failure, and hypertension [45-47]. Bomfim et al. [48] reported that TRL4 contributes to blood pressure regulation and vascular contraction in SHR. In fact, cardiac TLR4 expression is augmented in old SHR (15 weeks or older), but not in young SHR or in normotensive Wistar-Kyoto rat. Similarly, TLR4 protein expression in mesenteric resistance arteries is higher in old SHR than in Wistar-Kyoto rats or in young SHR (5-week-old) rats [49]. 
Bomfim et al. $[48,49]$ suggested that TLR4 activation contributes to increased blood pressure and vascular contractility; in addition, TRL4 inhibition reduces vascular inflammation in SHR. TLR4 signaling leads to the activation of NF- $\kappa \mathrm{B}$ and transcription of the gene involved in inflammatory responses via production of renal reactive oxygen species and expression of IL-6 cytokine in SHR [49]. Production of renal reactive oxygen species, activation of NF- $\kappa B$, and cytokine release all together have a fundamental role in renal damage [49]. Additionally, TLR4 plays a key role in hypertension-associated remodeling and end-organ damage via proinflammatory cytokines (IL-1 $\beta$ and TNF- $\alpha$ ) in SHR [50]. TLR4 signaling in the hypothalamic paraventricular nucleus of the brain might be one of the main factors for hypertension development and cardiac remodeling in SHR [51].

TLRs have been implicated in rat kidney diseases. High expression of TLR4 in the glomerular basement membrane, proximal convoluted tubules, and renal interstitial area in Sprague-Dawley rats suggests that TLR4 may activate the immune-inflammatory reaction in diabetic nephropathy [52]. Furthermore, TRL is stimulated by pathogen-associated molecular patterns and by endogenous TLR ligands provided by injured cells. In particular, Lim et al. [53] studied the influence of cyclosporine A (CsA)-induced renal injury on TLR expression. They concluded that CsA-induced renal injury stimulates components of innate immunity, suggesting a close association between CsA-induced renal injury and activation of innate immunity, via TLR-signaling pathway (i.e., increased myeloid differentiation primaryresponse protein 88 [MyD88], NF- $\kappa \mathrm{B}$, and activator protein-1). In this context, Lv et al. [54] demonstrated the overreactions of LR4-MyD88-NF- $\mathrm{KB}$-dependent innate immunity under high glucose condition, suggesting that TLR 4 activates the immune-inflammatory reaction in diabetic nephropathy.

Based on this information extracted from animal models, we propose that cardiac dendritic and renal DCs play a mutual role in type 2 and type 4 CRS (Fig. 1).

\section{DCs and Ischemia/Perfusion Injury: Potential Link with Type 1 or Type 3 CRS}

Many animal studies on acute cardiac or acute renal dysfunction have been studied and reported in the literature. However, the authors either did not address the function of the other organ of interest or the models they used did not mimic the exact characteristics of clinical type 1 and type 3 CRS. In fact, the heterogeneous character of heart and renal dysfunction in humans limits the possibilities of complete reproduction of these syndromes in animal models. Table 1 presents some animal models with separate ischemia/reperfusion (I/R) injury in the heart or kidney [21, 22, 55-59] that may be used to clarify the emerging role of DCs in type 1 or 3 CRS in humans. However, in these animal studies, there is no direct evidence demonstrating the role of DCs in the bidirectional interconnection between cardiac and renal I/R injury (i.e., from one organ I/R leading to another organ I/R injury), characterizing types 1 and 3 CRS. In spite of this fact, DCs are likely involved in types 1 and 3 CRS. In rat models with acute myocardial ischemic injury without perfusion injury $[21,22]$ and in rat models with renal I/R injury [55], TLR2 and TLR4 activation, inflammatory cytokine release (IFN- $\gamma$ ), immunosuppressive cytokine release (such as IL-10), and a cascade of DCs and T cell activation were all concomitantly observed. All these data confirm that I/R injury rapidly activates the innate immune response. Furthermore, Dong et al. [60] demonstrated that after I/R injury, renal DCs produce the proinflammatory cytokines/chemokines TNF- $\alpha$, IL-6, MCP-1, and regulated on activation, normal T cell expressed and secreted (RANTES). Furthermore, the depletion of DCs prior to I/R injury significantly reduced the kidney levels of TNF- $\alpha$ produced after the injury. In contrast, recent work showed the deleterious action of DCs during kidney injury induced by hypertensive stimuli $[61,62]$. These findings suggest that 
Table 1. Animal models with ischemia/reperfusion (I/R) injury in separate organs, either the heart or kidney

\begin{tabular}{|c|c|c|c|c|}
\hline $\begin{array}{l}\text { First author } \\
\text { [Ref.], year }\end{array}$ & Models & Species & Major findings & Pathogenic implications \\
\hline $\begin{array}{l}\text { Zhang [21], } \\
1993\end{array}$ & $\begin{array}{l}\text { Myocardial } \\
\text { ischemic injury }\end{array}$ & Male SD rats & $\begin{array}{l}\text { Significant increase in } \mathrm{OX}^{+} \mathrm{DCs}(\mathrm{MHC} \mathrm{II}), \mathrm{ED} 2^{+} \text {macrophages, } \\
\text { and } \mathrm{W} 3 / 25^{+} \mathrm{T} \text { help cells; peaked at days } 7-14\end{array}$ & $\begin{array}{l}\text { Cardiac ischemia activates DCs and } \\
\text { resultant immune response }\end{array}$ \\
\hline $\begin{array}{l}\text { Naito }[22] \\
2008\end{array}$ & $\begin{array}{l}\text { Myocardial } \\
\text { ischemic injury }\end{array}$ & $\begin{array}{l}\text { Male Wistar } \\
\text { rats }\end{array}$ & $\begin{array}{l}\text { The increased numbers of } 0 \times 62^{+} \text {DCs, heat shock protein } 70 \text {, } \\
\text { TLR2 and TLR4, and IFN- } \gamma \text { expression are reduced by G-CSF; } \\
\text { IL-10 expression is increased by G-CSF and decreased by GM-CSF }\end{array}$ & $\begin{array}{l}\text { Cardiac DCs exert modulating } \\
\text { effects on LV remodeling MI by } \\
\text { G-CSF improvement or GM-CSF } \\
\text { exacerbation }\end{array}$ \\
\hline $\begin{array}{l}\text { Kim }[55], \\
2005\end{array}$ & Renal I/R injury & Male SD rats & $\begin{array}{l}\text { Significant increase in } \mathrm{OX}^{+} \mathrm{DCs}(\mathrm{MHC} \mathrm{II}) \text { and } \mathrm{OX} 62^{+} \mathrm{DCs} \text {, } \\
\text { peaking at days } 3-5 \text { after I/R injury; renal I/R injury increases } \\
\text { TLR2 and TLR4 mRNA protein expression; renal I/R also } \\
\text { reduces TLR ligand (HSP70) }\end{array}$ & $\begin{array}{l}\text { Renal I/R injury rapidly activates } \\
\text { innate immune response }\end{array}$ \\
\hline $\begin{array}{l}\text { Wu [56], } \\
2006\end{array}$ & Renal I/R injury & SD rats & $\begin{array}{l}\text { Significant increase in peripheral blood monocyte-derived DCs, } \\
\text { expression of DC surface markers of CD11c, CD80, CD86, MHC II } \\
\text { (LA), and IL-12 production at day } 2 \text { after I/R injury }\end{array}$ & $\begin{array}{l}\text { DC progenitors migrate to kidney via } \\
\text { peripheral blood following I/R injury }\end{array}$ \\
\hline $\begin{array}{l}\text { Wu [57], } \\
2006\end{array}$ & Renal I/R injury & SD rats & $\begin{array}{l}\text { Significant decrease in bone marrow-derived DCs, but increase } \\
\text { in peripheral blood monocyte-derived DCs; increase in CD } 11 \mathrm{c}^{+} \text {, } \\
\text { CD } 80^{+} \text {, and } C D 86^{+} \text {DCs in the outer medulla of the injured kidney }\end{array}$ & $\begin{array}{l}\text { Bone marrow DC progenitors } \\
\text { migrate to the outer medulla (the } \\
\text { area susceptible to I/R injury) of the } \\
\text { kidney following I/R injury }\end{array}$ \\
\hline $\begin{array}{l}\text { Di Giorno [58], } \\
2006\end{array}$ & Renal I/R injury & $\begin{array}{l}\text { Male C57BL } \\
6 \text { mice }\end{array}$ & $\begin{array}{l}\text { Renal I/R injury increases CD } 11 \mathrm{c}^{+} \mathrm{DCs}, \mathrm{CD} 4^{+} \text {and } \mathrm{CD} 8^{+} \mathrm{T} \text { cells, } \\
\text { and upregulates expression of MHC class I and II molecules; } \\
\mathrm{N} \text {-acetyl-cysteine reduces CD } 11 \mathrm{c}^{+} \mathrm{DCs} \text { and MHC class II } \\
\text { expression }\end{array}$ & $\begin{array}{l}\mathrm{N} \text {-acetyl-cysteine decreases renal DC } \\
\text { infiltration }\end{array}$ \\
\hline $\begin{array}{l}\text { Dong }[60] \\
2007\end{array}$ & Renal I/R injury & C57BL/mice & $\begin{array}{l}\text { Renal F } 4 / 80^{+} \mathrm{DCs} \text { are predominant TNF- } \alpha \text {-secreting cells in } \\
\text { early renal I/R injury }\end{array}$ & $\begin{array}{l}\text { Renal DCs contribute to early release } \\
\text { of innate immune response to I/R } \\
\text { injury }\end{array}$ \\
\hline $\begin{array}{l}\text { Kim [59], } \\
2010\end{array}$ & Renal I/R injury & C57BL/6 mice & $\begin{array}{l}\mathrm{CD} 11 \mathrm{c}^{+} \mathrm{F} 4 / 80^{+} \mathrm{DC} \text { depletion induces higher tissue levels of } \\
\text { pro-inflammatory cytokines and lower level of IL-10 }\end{array}$ & $\begin{array}{l}\text { Renal } \mathrm{CD} 11 \mathrm{c}^{+} / \mathrm{F} 4 / 80^{+} \mathrm{DC} \text { subset } \\
\text { contribute to the recovery process of } \\
\text { AKI }\end{array}$ \\
\hline
\end{tabular}

DCs, dendritic cells; G-CSF, granulocyte colony-stimulating factor; GM-CSF, granulocyte-macrophage colony-stimulating factor; SD, Sprague-Dawley; LV, left ventricle; MHC, major histocompatibility complex; TLR2 or TLR4, Toll-like receptor 2 or 4.

DCs participate in the activation and initiation of immune response and are a key link between innate and adaptive immune responses for myocardial and renal I/R injury. Unfortunately, there are no specific studies about DC depletion in CRS and in heart-kidney cross talk.

\section{The Role of DCs in Type 5 CRS}

In a mouse model of sepsis multiple-organ dysfunction syndrome (MODS), in the early stage of injury, splenic DCs were mainly activated and increased, and splenic DCs matured to activate lymphocytes to generate the immune response: the immune activation of active DCs was predominant at this stage. At the same time, negative costimulatory molecules were highly expressed, and they have a negative regulatory effect and inhibit the overexpression of immune activity. In the later stage, the DC immune activation function decreased. In addition, the programmed cell death receptor (PD-1) and its ligand (PD-L1) expressions continuously increased, indicating that early active DCs had converted into tolerant DCs. In the MODS stage, the immune tolerance caused by the DCs' highly negative costimulatory molecules was predominant. The results of this study preliminarily suggest that DCs can regulate T cell function by different costimulatory molecules (i.e., PD-1/PD-L1 pathway) [63].

Lipopolysaccharide (LPS) downregulates the expression of surface markers (CD11c and CD11b) on the splenic DC subset. These changes in DC markers are likely to represent an 
altered function of DCs in the setting of inflammatory conditions [64]. In a mice model, the loss of immature DCs and the inability of mature splenic DCs to produce Th1 cytokines (i.e., IL-12) result in an immunosuppressive effect [65]. Additionally, in LPS-induced sepsis, endogenous glucocorticoids (immunosuppressive hormones) protect mice from LPS-induced septic shock by suppressing DC production of IL-12 (a cytokine required for IFN- $\gamma$ production and lethality in LPS-induced septic shock) [65]. Kobayashi et al. [66] reported that B and T lymphocyte attenuator (CD272) inhibits LPS-induced endotoxic shock by suppressing TLR4 signaling and proinflammatory cytokine production in DCs. These findings suggest that the cellular and molecular mechanisms responsible for endotoxin tolerance are multifactorial and likely involve negative feedback at multiple levels in multiple cell types.

\section{The Potential of Human Study on DCs}

On the basis of animal studies on DCs, further research is warranted to determine the emerging role of DCs in human CRS, to prove both detrimental and beneficial effects of DCs on humans, and to explore their potential as therapeutic targets. Therefore, a better understanding of the interplay between the immune system and cardiac/renal dysfunction will be critical for developing novel therapeutic treatments and innovative approaches for monitoring the progression of CRS. There is growing evidence to suggest that the phenotypes and functions of DCs in animals and humans are similar in some aspects. For example, loss of DCs has been observed in septic patients and in experimental sepsis models [65]. The B and T lymphocyte attenuator directly inhibits LPS response in DCs; thus, agonistic agents for the B and $\mathrm{T}$ lymphocyte attenuator might have therapeutic potential for LPS-induced endotoxic shock [66]. In AMI of patients, DCs, macrophages, and T cells initiate an immune response against cardiac antigens, leading to further myocardial damage [67]. Human DCs are characterized by HLA-DR (MHC class II) and spindle-shaped morphology with long, slender, dendritic processes, which are in close contact with myocytes. Yokoyama et al. [1] reported that, in the human heart, cardiac DCs may be recruited in the acute phase of myocarditis, and seem to play an important role in the subsequent immunoresponse. Furthermore, in acute myocarditis, DCs present altered cardiac myosin molecules released from injured cardiomyocytes to helper T lymphocytes. Interestingly, a protective role of DCs was detected in postmyocardial infarction inflammation [68]. Therefore, it should be reminded that the immune system of mice and humans differs in considerable aspects, and more studies are required in patients because many pathogenic factors, tumors, microbes, or allergens, a stimulus for autoimmune or autoinflammatory disease, cannot easily or totally be modeled in mice.

\section{Can ECs Function as Antigen-Presenting Cells in CRS?}

Endothelial cells (ECs) are located at the interface of blood and tissues, and display regulatory activities toward coagulation, inflammation, and vascular homeostasis. By expressing MHC class I and II antigens, ECs also contribute to immune responses [69]. Like DC activation and maturation, EC activation and dysfunction play a pivotal role in the pathogenesis of CRS [14]. Regarding immune responses in CRS, it is unknown whether ECs may serve as antigenpresenting cells or act synergistically with DCs to actively participate in innate and adaptive immune responses. In this context, little is known about CRS in humans. However, there is growing evidence to suggest that cultured human ECs act as nonprofessional antigenpresenting cells that are likely capable of presenting antigens to T cells [70-72]. ECs are so-called nonprofessional antigen-presenting cells because they appear to be less potent 
stimulators of $\mathrm{T}$ cells than conventional professional antigen-presenting cells (e.g., DCs, monocytes, macrophages, and B cells). Therefore, the number of T cells activated by ECs is far fewer than those activated by professional antigen-presenting cells [5]. In the setting of ECs as antigen-presenting cells, attention has been focused on cytokine-induced endothelial activation, cytokine-increased MHC class I or II molecules in the endothelium, and cytokineinduced cell adhesion molecules (e.g., ICAM-1, ICAM-2, VCAM-1, E-selectin, p-selectin) in the endothelium. It has been shown that cytokines such as interferon family (IFN- $\alpha$, IFN- $\beta$, and IFN- $\gamma$ ), TNF family (TNF- $\alpha$, TNF- $\beta$ ), IL-1, and IL-2 act to increase MHC class I or II antigen expression in the endothelium [71]. In particular, TNF can enhance IFN- $\gamma$-induced MHC class I and II antigen expression on human ECs [70], which can directly activate resting CD8 T cells; further, IFN- $\gamma$-pretreated ECs can activate CD4 T cells [71]. These actions enhance the ability of ECs to participate in immune reactions [71].

In the setting of an immune rejection reaction associated with transplantation, it has been suggested that human ECs as antigen-presenting cells participate in delayed hypersensitivity [71]. In this context, there is a difference in MHC class II antigens between rodent models of allograft rejection and patient transplant rejection [71]. Both rodent and human ECs express MHC I antigens. In rodents, the unique source of donor MHC class II is bone marrow-derived passenger leukocytes (DCs and macrophages). In contrast, in humans, endothelium located in the capillaries, arterioles, coronary arteries, and venules (but not in the aorta, pulmonary artery, and saphenous vein) contains MHC class II (HLA-DR and DP) antigens [71]. These differences may explain why it is easier to suppress transplant rejection in rodents than in humans [71]. The phenotypic properties of human ECs, their response to cytokines, and their ability to stimulate resting $\mathrm{T}$ cells allow human ECs to act as antigen-presenting cells in allograft rejection following cardiac and renal transplantation [71].

Recent evidence suggests that ECs actively participate in innate and adaptive immune responses [73]. Furthermore, ECs are a passive target of the host immune response but also an active player in lymphocyte activation [74]. Recent data reported that IFN- $\gamma$ stimulates endothelial cells that become capable of inducing Foxp $3^{+}$regular T cells, crucial mediators of immune tolerance [74]. Additionally, ECs express a set of MHC class I-like or structuralrelated molecules, such as HLA-E, MHC class I-related chain A, and the endothelial protein C receptor; these new molecules provide multiple and unique function to endothelial cells [69]. These facts along with the new concept of endothelial plasticity suggest that ECs are dynamic cells that respond to extracellular environmental changes and play a meaningful role in immune system function [73].

The above-cited information about human ECs allows to hypothesize that ECs are likely to be nonprofessional antigen-presenting cells in human CRS. Our observations, in addition to data on endothelial dysfunction [14] and heart-kidney cross talk in the setting of immune system cells [7], suggest that professional antigen-presenting cells (DCs, monocytes, macrophages, B cells), nonprofessional antigen-presenting cells (ECs), and other immune cells (lymphocytes, neutrophils, etc.) play an important role in innate and adaptive immune responses to CRS. In particular, experimental data demonstrated that a defective regulation of monocyte apoptosis and an immune-mediated mechanism play a fundamental role in the pathophysiology of type 1 CRS [75].

\section{Conclusion}

Our knowledge of DC biology is likely to be markedly extended to dissect the pathogenic processes of CRS for prevention and treatment. Especially, progress has been made in DC biology of animal models. Evidence from animal models suggests that DCs play a role in CRS 
types 2 and 4, and they may also be involved in types 1, 3, and 5 . Unfortunately, very little information is available with regard to the precise mechanism whereby DCs contribute to CRS. Further study is need to elucidate the role of DCs in CRS; particularly, the molecular mechanism involved in the tissue dysfunction observed in these syndromes. In addition, new animal models, which may include both heart and kidney disease and involve cardiac and renal DCs, the interaction of DCs and ECs, and cross talk between DCs and TLR4 or TLR2 are necessary to better understand CRS. Further investigations, further studies, further in vitro experiments, and specific animal models are therefore necessary to better understand this pathophysiological process and the therapeutic and prognostic implications for DCs in all types of CRS.

All these approaches help us to understand the exact role of DCs in CRS and the exact molecular and submolecular mechanisms involved. These approaches are very important and fundamental to explore how DCs contribute to tissue dysfunction in heart and kidney in CRS. Finally, there is still a lack of translational investigations in human studies. Resolving this issue is crucial because translation can prove both the detrimental and beneficial effects of DCs on humans and discover the underlying pathogenetic mechanisms. In addition, answering the many open questions with regard to the role of DCs in immune tolerance could lead to the development of novel therapies for the prevention and treatment of CRS.

\section{Acknowledgement}

The authors thank Alan D. Knapton (US FDA) for the technical assistance in figure preparation. The authors also thank Adam Stephens (the Publications Office, Baylor Scoot \& White Health) for expert assistance in editing the manuscript.

\section{Statement of Ethics}

This work did not involve human subjects or animals and was exempt from review by Baylor Institutional Review Board.

\section{Disclosure Statement}

There are no conflicts of interest to disclose.

\section{Funding Sources}

Funding for this work was obtained from Baylor Heart and Vascular Institute.

\section{References}

1 Yokoyama H, Kuwao S, Kohno K, Suzuki K, Kameya T, Izumi T: Cardiac dendritic cells and acute myocarditis in the human heart. Jpn Circ J 2000;64:57-64.

2 Zhang Y, Zhang C: Role of dendritic cells in cardiovascular diseases. World J Cardiol 2010;2:357-364.

3 Hochheiser K, Tittel A, Kurts C: Kidney dendritic cells in acute and chronic renal disease. Int J Exp Pathol 2011; 92:193-201.

4 Dieterlen MT, John K, Reichenspurner H, Mohr FW, Barten MJ: Dendritic cells and their role in cardiovascular diseases: a view on human studies. J Immunol Res 2016;2016:5946807.

5 Ronco C, Di Lullo L: Cardiorenal syndrome. Heart Fail Clin 2014;10:251-280. 
6 Ronco C, Haapio M, House AA, Anavekar N, Bellomo R: Cardiorenal syndrome. J Am Coll Cardiol 2008;52: 1527-39.

7 Virzi G, Day S, de Cal M, Vescovo G, Ronco C: Heart-kidney crosstalk and role of humoral signaling in critical illness. Crit Care 2014;18:201.

8 Bongartz LG, Cramer MJ, Braam B: The cardiorenal connection. Hypertension 2004;43:e14.

9 Shestakova MV, Jarek-Martynowa IR, Ivanishina NS, Kuharenko SS, Yadrihinskaya MN, Aleksandrov AA, et al: Role of endothelial dysfunction in the development of cardiorenal syndrome in patients with type 1 diabetes mellitus. Diabetes Res Clin Pract 2005;68(suppl 1):S65-S72.

10 Hatamizadeh P, Fonarow GC, Budoff MJ, Darabian S, Kovesdy CP, Kalantar-Zadeh K: Cardiorenal syndrome: pathophysiology and potential targets for clinical management. Nat Rev Nephrol 2013;9:99-111.

11 Cohen L: The cardiorenal syndrome: pathophysiologic crosstalk, outcomes, and treatment targets. Cardiovasc Hematol Disord Drug Targets 2014;14:170-176.

12 Camuglia AC, Maeder MT, Starr J, Farrington C, Kaye DM: Impact of N-acetylcysteine on endothelial function, B-type natriuretic peptide and renal function in patients with the cardiorenal syndrome: a pilot cross over randomised controlled trial. Heart Lung Circ 2013;22:256-259.

13 Larsen TR, Kinni V, Zaks J, David S, McCullough PA: A lethal case of influenza and type 5 cardiorenal syndrome. Blood Purif 2013;36:112-115.

14 Zhang J, Bottiglieri T, McCullough PA: The central role of endothelial dysfunction in cardiorenal syndrome. Cardiorenal Med 2017;7:104-117.

15 Rajapakse NW, Nanayakkara S, Kaye DM: Pathogenesis and treatment of the cardiorenal syndrome: implications of L-arginine-nitric oxide pathway impairment. Pharmacol Ther 2015;154:1-12.

16 Bertoluci MC, Ce GV, da Silva AM, Wainstein MV, Boff W, Punales M: Endothelial dysfunction as a predictor of cardiovascular disease in type 1 diabetes. World J Diabetes 2015;6:679-692.

17 Tomiyama H, Yamashina A: Vascular dysfunction: a key player in chronic cardio-renal syndrome. Intern Med 2015;54:1465-1472.

18 Hart DN, Fabre JW: Demonstration and characterization of Ia-positive dendritic cells in the interstitial connective tissues of rat heart and other tissues, but not brain. J Exp Med 1981;154:347-361.

19 Steiniger B, Klempnauer J, Wonigeit K: Phenotype and histological distribution of interstitial dendritic cells in the rat pancreas, liver, heart, and kidney. Transplantation 1984;38:169-174.

20 Forbes RD, Parfrey NA, Gomersall M, Darden AG, Guttmann RD: Dendritic cell-lymphoid cell aggregation and major histocompatibility antigen expression during rat cardiac allograft rejection. J Exp Med 1986;164:12391258.

21 Zhang J, Yu ZX, Fujita S, Yamaguchi ML, Ferrans VJ: Interstitial dendritic cells of the rat heart. Quantitative and ultrastructural changes in experimental myocardial infarction. Circulation 1993;87:909-920.

22 Naito K, Anzai T, Sugano Y, Maekawa Y, Kohno T, Yoshikawa T, et al: Differential effects of GM-CSF and G-CSF on infiltration of dendritic cells during early left ventricular remodeling after myocardial infarction. J Immunol 2008;181:5691-5701.

23 Anzai A, Anzai T, Nagai S, Maekawa Y, Naito K, Kaneko H, et al: Regulatory role of dendritic cells in postinfarction healing and left ventricular remodeling. Circulation 2012;125:1234-1245.

24 Anzai T: Post-infarction inflammation and left ventricular remodeling: a double-edged sword. Circ J 2013;77: 580-587.

25 Zhang J, Herman EH, Ferrans VJ: Effects of ICRF-186 [(L)1, 2-bis(3, 5-dioxopiperazinyl-1-yl)propane] on the toxicity of doxorubicin in spontaneously hypertensive rats. Toxicology 1994;92:179-192.

26 Zhang J, Herman EH, Ferrans VJ: Dendritic cells in the hearts of spontaneously hypertensive rats treated with doxorubicin with or without ICRF-187. Am J Pathol 1993;142:1916-1926.

27 Cao Q, Wang Y, Wang XM, Lu J, Lee VW, Ye Q, et al. Renal F4/80+ CD11c+ mononuclear phagocytes display phenotypic and functional characteristics of macrophages in health and in Adriamycin nephropathy. J Am Soc Nephrol 2015;26:349-363.

28 Muller DN, Shagdarsuren E, Park JK, Dechend R, Mervaala E, Hampich F, et al: Immunosuppressive treatment protects against angiotensin II-induced renal damage. Am J Pathol 2002;161:1679-1693.

29 Kaissling B, Le Hir M: Characterization and distribution of interstitial cell types in the renal cortex of rats. Kidney Int 1994;45:709-720.

30 Austyn JM, Hankins DF, Larsen CP, Morris PJ, Rao AS, Roake JA: Isolation and characterization of dendritic cells from mouse heart and kidney. J Immunol 1994;152:2401-2410.

31 Mahnke K, Schmitt E, Bonifaz L, Enk AH, Jonuleit H: Immature, but not inactive: the tolerogenic function of immature dendritic cells. Immunol Cell Biol 2002;80:477-483.

32 Dudek AM, Martin S, Garg AD, Agostinis P: Immature, semi-mature, and fully mature dendritic cells: toward a DC-cancer cells interface that augments anticancer immunity. Front Immunol 2013;4:438.

33 Steptoe RJ, Patel RK, Subbotin VM, Thomson AW: Comparative analysis of dendritic cell density and total number in commonly transplanted organs: morphometric estimation in normal mice. Transplant Immunol 2000;8:49-56.

34 Teteris SA, Engel DR, Kurts C: Homeostatic and pathogenic role of renal dendritic cells. Kidney Int 2011;80: 139-145.

35 Tadagavadi RK, Reeves WB: Renal dendritic cells ameliorate nephrotoxic acute kidney injury. J Am Soc Nephrol 2010;21:53-63. 
36 Tadagavadi RK, Reeves WB: Endogenous IL-10 attenuates cisplatin nephrotoxicity: role of dendritic cells. J Immunol 2010;185:4904-4911.

37 Rogers NM, Ferenbach DA, Isenberg JS, Thomson AW, Hughes J: Dendritic cells and macrophages in the kidney: a spectrum of good and evil. Nat Rev Nephrol 2014;10:625-643.

38 Shortman K, Liu YJ: Mouse and human dendritic cell subtypes. Nat Rev Immunol 2002;2:151-161.

39 Schlichting CL, Schareck WD, Weis M: Renal ischemia-reperfusion injury: new implications of dendritic cellendothelial cell interactions. Transplant Proc 2006;38:670-673.

40 Robert C, Fuhlbrigge RC, Kieffer JD, Ayehunie S, Hynes RO, Cheng G, et al: Interaction of dendritic cells with skin endothelium: a new perspective on immunosurveillance. J Expl Med 1999;189:627-636.

41 Weis M, Schlichting CL, Engleman EG, Cooke JP: Endothelial determinants of dendritic cell adhesion and migration: new implications for vascular diseases. Arterioscler Thromb Vasc Biol 2002;22:1817-1823.

42 Sozzani S, Rusnati M, Riboldi E, Mitola S, Presta M: Dendritic cell-endothelial cell cross-talk in angiogenesis. Trends Immunol 2007;28:385-392.

43 Zhu WG, Li S, Lin LQ, Yan H, Fu T, Zhu JH: Vascular oxidative stress increases dendritic cell adhesion and transmigration induced by homocysteine. Cell Immunol 2009;254:110-116.

44 Pasare C, Medzhitov R: Toll-like receptors: linking innate and adaptive immunity. Microbes Infect 2004;6: 1382-1387.

45 de Kleijn D, Pasterkamp G: Toll-like receptors in cardiovascular diseases. Cardiovasc Res 2003;60:58-67.

46 Chao W: Toll-like receptor signaling: a critical modulator of cell survival and ischemic injury in the heart. Am J Physiol Heart Circ Physiol 2009;296:H1-H12.

47 Eissler R, Schmaderer C, Rusai K, Kuhne L, Sollinger D, Lahmer T, et al: Hypertension augments cardiac Tolllike receptor 4 expression and activity. Hypertens Res 2011;34:551-558.

48 Bomfim GF, Dos Santos RA, Oliveira MA, Giachini FR, Akamine EH, Tostes RC, et al: Toll-like receptor 4 contributes to blood pressure regulation and vascular contraction in spontaneously hypertensive rats. Clin Sci (Lond) 2012;122:535-543.

49 Bomfim GF, Echem C, Martins CB, Costa TJ, Sartoretto SM, Dos Santos RA, et al: Toll-like receptor 4 inhibition reduces vascular inflammation in spontaneously hypertensive rats. Life Sci 2015;122:1-7.

50 Echem C, Bomfim GF, Ceravolo GS, Oliveira MA, Santos-Eichler RA, Bechara LR, et al: Anti-toll like receptor 4 (TLR4) therapy diminishes cardiac remodeling regardless of changes in blood pressure in spontaneously hypertensive rats (SHR). Int J Cardiol 2015;187:243-245.

51 Dange RB, Agarwal D, Teruyama R, Francis J: Toll-like receptor 4 inhibition within the paraventricular nucleus attenuates blood pressure and inflammatory response in a genetic model of hypertension. J Neuroinflamm $2015 ; 12: 31$

52 Liu SY, Nie XZ, Zhou WY, Chen J: Expression and effect of TLR4 in rats with diabetic nephropathy. Asian Pac J Trop Med 2013;6:635-639.

53 Lim SW, Li C, Ahn KO, Kim J, Moon IS, Ahn C, et al: Cyclosporine-induced renal injury induces toll-like receptor and maturation of dendritic cells. Transplantation 2005;80:691-699.

54 Lv J, Chen Q, Shao Y, Chen Y, Shi J: Cross-talk between angiotensin-II and Toll-like receptor 4 triggers a synergetic inflammatory response in rat mesangial cells under high glucose conditions. Biochem Biophys Res Commun 2015;459:264-269.

55 Kim BS, Lim SW, Li C, Kim JS, Sun BK, Ahn KO, et al: Ischemia-reperfusion injury activates innate immunity in rat kidneys. Transplantation 2005;79:1370-1377.

56 Wu CJ, Sheu JR, Chen HH, Liao HF, Yang YC, Yang S, et al: Modulation of monocyte-derived dendritic cell differentiation is associated with ischemic acute renal failure. J Surg Res 2006;132:104-111.

57 Wu CJ, Sheu JR, Chen HH, Liao HF, Yang YC, Yang S, et al: Renal ischemia/reperfusion injury inhibits differentiation of dendritic cells derived from bone marrow monocytes in rats. Life Sci 2006;78:1121-1128.

58 Di Giorno C, Pinheiro HS, Heinke T, Franco MF, Galante NZ, Pacheco-Silva A, et al: Beneficial effect of N-acetylcysteine on renal injury triggered by ischemia and reperfusion. Transplant Proc 2006;38:2774-2776.

59 Kim MG, Boo CS, Ko YS, Lee HY, Cho WY, Kim HK, et al: Depletion of kidney CD11c+ F4/80+ cells impairs the recovery process in ischaemia/reperfusion-induced acute kidney injury. Nephrol Dial Transplant 2010;25: 2908-2921.

60 Dong X, Swaminathan S, Bachman LA, Croatt AJ, Nath KA, Griffin MD: Resident dendritic cells are the predominant TNF-secreting cell in early renal ischemia-reperfusion injury. Kidney Int 2007;71:619-628.

61 Kirabo A, Fontana V, de Faria AP, Loperena R, Galindo CL, Wu J, et al: DC isoketal-modified proteins activate T cells and promote hypertension. J Clin Invest 2014;124:4642-4656.

62 Itani HA, Xiao L, Saleh MA, Wu J, Pilkinton MA, Dale BL, et al: CD70 exacerbates blood pressure elevation and renal damage in response to repeated hypertensive stimuli. Circ Res 2016;118:1233-1243.

63 Liu Q, Lu JY, Wang XH, Qu BJ, Li SR, Kang JR: Changes in the PD-1 and PD-L1 expressions of splenic dendritic cells in multiple-organ dysfunction syndrome mice and their significance. Genet Mol Res 2014;13:7666-7672.

64 Griffiths KL, Tan JK, O'Neill HC: Characterization of the effect of LPS on dendritic cell subset discrimination in spleen. J Cell Mol Med 2014;18:1908-1912.

65 Li CC, Munitic I, Mittelstadt PR, Castro E, Ashwell JD: Suppression of dendritic cell-derived IL-12 by endogenous glucocorticoids is protective in LPS-induced sepsis. PLoS Biol 2015;13:e1002269. 
66 Kobayashi Y, Iwata A, Suzuki K, Suto A, Kawashima S, Saito Y, et al: B and T lymphocyte attenuator inhibits LPS-induced endotoxic shock by suppressing Toll-like receptor 4 signaling in innate immune cells. Proc Natl Acad Sci USA 2013;110:5121-5126.

67 Yilmaz A, Dietel B, Cicha I, Schubert K, Hausmann R, Daniel WG, et al: Emergence of dendritic cells in the myocardium after acute myocardial infarction - implications for inflammatory myocardial damage. Int J Biomed Sci 2010;6:27-36.

68 Nagai T, Honda S, Sugano Y, Matsuyama TA, Ohta-Ogo K, Asaumi Y, et al: Decreased myocardial dendritic cells is associated with impaired reparative fibrosis and development of cardiac rupture after myocardial infarction in humans. J Am Heart Assoc 2014;3:e000839.

69 Gavlovsky PJ, Tonnerre P, Guitton C, Charreau B: Expression of MHC class I-related molecules MICA, HLA-E and EPCR shape endothelial cells with unique functions in innate and adaptive immunity. Hum Immunol 2016; 77:1084-1091.

70 Epperson DE, Pober JS: Antigen-presenting function of human endothelial cells. Direct activation of resting CD8 T cells. J Immunol 1994; 153:5402-5412.

71 Pober JS, Cotran RS: Cytokines and endothelial cell biology. Physiol Rev 1990;70:427-451.

72 Rose ML: Endothelial cells as antigen-presenting cells: role in human transplant rejection. Cell Mol Life Sci 1998;54:965-978.

73 Mai J, Virtue A, Shen J, Wang H, Yang XF: An evolving new paradigm: endothelial cells - conditional innate immune cells. J Hematol Oncol 2013;6:61.

74 Piotti G, Palmisano A, Maggiore U, Buzio C: Vascular endothelium as a target of immune response in renal transplant rejection. Front Immunol 2014;5:505.

75 Pastori S, Virzi GM, Brocca A, de Cal M, Clementi A, Vescovo G, et al: Cardiorenal syndrome type 1: a defective regulation of monocyte apoptosis induced by proinflammatory and proapoptotic factors. Cardiorenal Med 2015;5:105-115. 